\title{
Aplikasi Agenda Surat Keluar dan Surat Masuk Berbasis Filing System
}

\author{
Wiwin Susanty*, Fikri Rahman, Taqwan Thamrin \\ Program Sistem Informasi, Fakultas Ilmu Komputer \\ Universitas Bandar Lampung \\ Lampung, INDONESIA \\ wiwin.susanty@ubl.ac.id*, fikri.17411032@student.ubl.ac.id, taqwanthamrin@ubl.ac.id
}

\begin{abstract}
This study aims to facilitate the organizers or staff or administrative staff to make an efficient and effective schedule. The benefit of this research is that it can improve the ease of scheduling and minimize problems for organizers in scheduling activities. This research method uses a Filing System which is an indicator of looking for letters based on the calendar, subject, letter number, and others when the letter is needed or needed. The data collection technique uses an approach technique or commonly called a qualitative technique, namely by means of observation to ensure that the company still performs scheduling activities manually. Then conducted interviews with the authorities in the correspondence section. The research location is at the Department of Culture and Sports of Bandar Lampung City. The result of this research is that if the organizer does the scheduling, it can save time, energy, and storage. because everything is done computerized.
\end{abstract}

Keywords: Organizer; Mail Management; Incoming Mail; Outgoing Mail; Filing System.

Abstrak - Penelitian ini bertujuan untuk memudahkan agendaris atau staf atau staf administrasi untuk melakukan pengagendaan yang efisien dan efektif. Manfaat dari penelitian ini adalah dapat meningkatkan kemudahan dalam pengagendaan dan meminimalkan masalah bagi agendaris dalam kegiatan pengagendaan. Metode penelitian ini menggunakan sistem filing yang merupakan indikator pencarian surat berdasarkan penanggalan, subjek, nomor surat, dan lain-lain pada saat surat dibutuhkan. Teknik pengumpulan data menggunakan teknik kualitatif yaitu dengan cara observasi untuk memastikan bahwa instansi masih melakukan kegiatan pengagendaan secara manual. Kemudian dilakukan wawancara dengan pihak yang berwenang di bagian korespondensi. Lokasi penelitian berada di Dinas Kebudayaan dan Olahraga Kota Bandar Lampung. Hasil dari penelitian ini adalah jika agendaris melakukan pengagendaan maka dapat menghemat waktu, tenaga, dan penyimpanan karena semuanya dilakukan secara komputerisasi.

Kata Kunci: Agendaris; Pengelolaan Surat; Surat Masuk; Surat Keluar; Filing System.

\section{Pendahuluan}

Surat keluar dan surat masuk merupakan komunikasi antar instansi atau organisasi yang sangat penting dalam keadministasian. pengelolaan agenda surat keluar dan surat masuk pada instansi yang masih menggunakan cara manual atau kovensional seperti menyimpan surat atau mencatat data data dalam bentuk agenda pembukuan yang disusun bertumpuk tumpuk, sehingga hal tersebut dapat menyebabkan kerusakan dan hilang pada berkas dan proses pencarian berkas memakan waktu bahkan bisa membuat kesulitan jika berkas sudah jangka waktu yang cukup lama.

Selain itu surat yang dicatat di agenda pembukuan menggunakan tulisan tangan yang dapat mengakibatkan pengulangan nomor surat, penanggalan yang salah. untuk mengatasi permasalahan yang ada peneliti membuat aplikasi sederhana yang menunjang kegiatan agenda surat keluar dan masuk menjadi lebih efisien dan efektif.

Pada aplikasi ini akan dibuat dalam bentuk website dengan menggunakan bahasa pemerograman $p h p$ dan penyimpanan menggunakan Database Xampp. metode yang digunakan adalah Filing System yang menjadi indikator pencarian berdasarkan penanggalan, perihal, nomor surat, dan lain-lain. Diharapkan aplikasi agenda surat keluar dan surat masuk sebagai aplikasi pencarian surat, pengelolaan surat, dan menjadi media penyimpanan yang lebih mudah dan terstruktur.

\section{Landasan Teori}

Penelitian [1] mengimplementasi rancang bangun sistem infomrasi surat yang pada awalnya masih menggunakan cara konvensional menjadi sistem informasi surat keluar dan masuk menggunakan metode SDLC dengan model waterfall (air terjun), sistem ini dirancang guna mempermudah dalam proses surat menyurat.

Penelitian [2] sistem manajemen dokumen paperless efektif dan berguna untuk mengefektifkan proses dokumentasi di kantor. Keuntungan utama adalah dapat memudahkan pencarian informasi yang dibutuhkan. Dengan Document Management System based on Paperless dapat mempercepat dan meningkatkan proses, 
mengurangi biaya dan mengurangi dampak lingkungan (Green Computing).

Penelitian [3] untuk meningkatkan keakuratan dan ke efesiensi pengambilan kembali dalam rangka kegiatan investigasi maupun referensi kedinasan maka dibutuhkan sebuah sistem pengelolaan surat. Dan metode yang digunakan dalam metode ini adalah Alphabetical Filing dan Chronology System digunakan dalam pengimplementasian sistem dikarnakan mudah dan sederhana.

Penelitian [4] untuk mendapatkan informasi pengetahuan tentang pengelolaan surat di perpustakaan kampus dibutuhkan pengelolaan surat tersebut. Proses pengelolaan ini lebih bertujuan untuk kegiatan komunikasi surat keluar dan surat masuk dari pihak yang bersangkutan.

Fungsi dari Filing System adalah untuk sebuah instansi maupun organisasi jadi lebih mempermudah dalam pencarian arsip serta menghemat tempat penyimpanan arsip. Kesimpulan fungsi Filing System yaitu akan membantu agendaris menghemat waktu dan tenaga dalam pengagendaan surat menyurat [5].

Basis data adalah sekumpulan fakta-fakta berupa uraian tabel yang saling berkaitan dan simpan kedalam penyimpanan media digital [6], [7].

Structure Query Language (SQL) adalah aplikasi komputer pengonsepan RDBMS (Relation Database Management System), terstuktur dengan Bahasa yang sederhana untuk membangun sebuah basis data [8]. MySQL adalah aplikasi DBMS (Database Management System) untuk menjalankan fungsi pengolahan data [10].

Chronoligcal Filing System adalah berkas sistem pencarian berdasarkan pertanggalan baik itu tahun, bulan atau hari. Disusun urut dan diklompokan sesuai pertanggalan. Alphabetic Filling System adalah berkas sistem pencarian berdasakan huruf abjad A-Z dalam surat keluar dan surat masuk diurutkan sesuai prihal, keterangan, nomor surat [9].

\section{Metodologi}

Metode penelitian adalah pemaparan proses pembuatan apliasi surat keluar dan masuk dengan menggunakan software visual studio code sebagai text editor yang dipakai lalu Bahasa pemerograman bypertext preprocessor (PHP) dan framework Laravel, kemudian dengan penentuan alur menggunakan flowchart, UseCase, Diagram activity. Untuk basis data yang dipakai kedalam aplikasi adalah menggunakan MySQL dengan software pendukung yaitu Xampp. Pengumpulan data menggunakan pendekatan kualitatif peneliti memperoleh data data dengan observasi mendatangi langsung ke instansi yang bersangkutan dengan penelitian ini berupa wawancara, form pertanyaan dan surat balasan dari instansi tersebut.

Analisis software dan hardware kebutuhan dalam proses pembuatan aplikasi yaitu: (a) Software; Vs Code (text editor), Xampp (MySQL dan Apache), dan PHP (Bahasa Pemerograman); (b) Hadrware; Laptop Thinkpad T430,
Processor intel core i5-3320M CPU 2.60 GHz, Memory 8,00 GB, dan Mouse dan Keyboard.

Analisis kebutuhan sistem dan perancangan sistem sendiri yaitu instalasi software Xampp untuk membuat database dan sekaligus membuat table yang dibutuhkan untuk membuat sebuh fitur dimana aplikasi dapat menjalankan kegiatan CRUD (Create Read Update Delete).

Analisis basis pengetahuan adalah proses pengumpulan data menggunakan teknik interakti dan pendekatan kualitatif seperti wawancara, observasi dan lembaran balasan proses wawancara. Peneliti melakukan proses penelitian ke Dinas Kepemudaan dan Olahraga Kota Bandar Lampung Provinsi Lampung, Indonesia melihat proses kegiatan masih dilakukan secara manual. Wawancara dilakukan secara langsung kepada pihak Dinas Kepemudaan dan Olahraga Kota Bandar Lampung. Hal-hal yang dikumpulkan adalah informasi tentang kegiatan surat menyurat; proses kegiatan surat menyurat; kendala dan masalah yang dialami ketika menggunakan proses secara manual, dan pengubahan proses manual menjadi aplikasi.

Analisis perancangan sistem adalah hal hal yang dibutuhkan untuk perancang sebuah apikasi surat keluar dan surat masuk sekaligus ada beberapa tahap yang perlu dilakukan untuk mencapai kebutuhan perancangan sebuah aplikasi.

\section{Hasil dan Pembahasan}

\section{A. Alur Sistem}

Alur sistem adalah sebagai gambaran berupa simbol simbol yang saling berkaitan satu sama lain memiliki fungsi disetiap simbolnya, bertujuan sebagai alur proses aplikasi yang akan berjalan sesuai apa yang dirancang dan dibuat. Alur pada Gambar 1 adalah alur sistem (flowchart) dari keseluruhan yang ada pada aplikasi yang akan dibuat.

Use Case adalah aktor adat pihak yang bersangkutan yang akan menggunakan aplikasi sebagai User. Dalam hal ini User/ penggunanya adalah agendaris atau staff atau staff administrasi pada instansi dinas kepemudaan Kota Bandar Lampung. Pengguna (User) yang akan melakukan pengelolaan atau pengarsipan terkait agenda surat baiksurat masuk maupun surat keluar, surat resmi maupun non resmi yang berhubungan dengan kedinasan pada Instansi dinas Kepemudaan di Kota Bandar Lampung. Sehingga dengan adanya aplikasi pengelolaan agenda surat ini yang sudah terkomputerisasi dapat memudahkan kegiatan pengarsipan serta merapihkan berkas dan sudah ada databasenya, Gambar 2.

Diagram activity adalah alur aktifitas yang akan dilakukan User dalam hal ini adalah agendaris/ staff/ pelaksana. Dalam hal ini aktifitas yang dilakukan oleh staff/pelaksana sudah terorganisir dan prosedurnya sudah jelas step by step apa yg harus dilakukan. Jadi pekerjaan/kegiatan yang dilakukan sesuan dengan unit dan jobdesnya masing-masing dan aplikasi dapat dijalankan dan digunakan sesuai dengan pengolahan datanya serta terstruktur. Aplikasi ini sesuai dengan DBMS dan Konsep RDBMS, Gambar 3. 


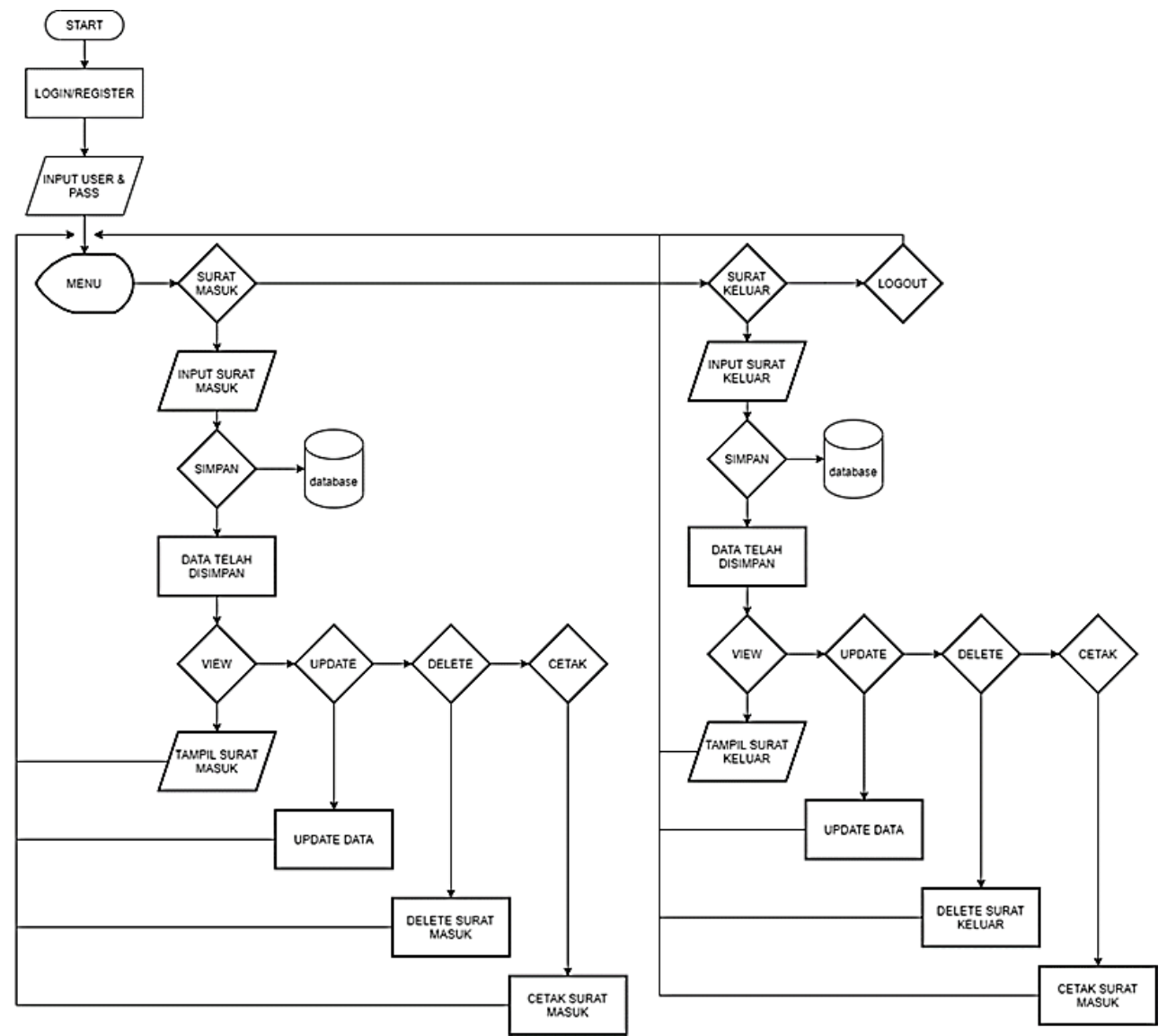

Gambar 1. Flowchart Aplikasi Surat Masuk dan Surat Keluar Berbasis Filing System

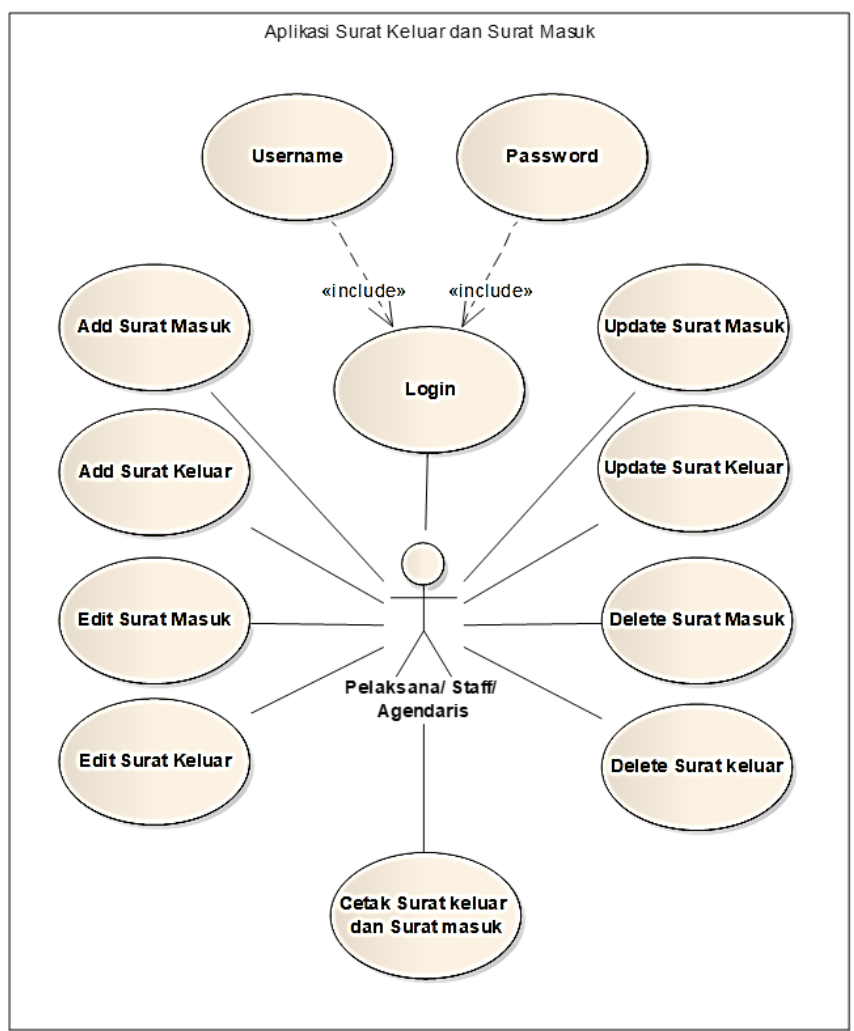

Gambar 2. Use Case Aplikasi Agenda Surat Masuk dan Surat Keluar Berbasis Filing System 


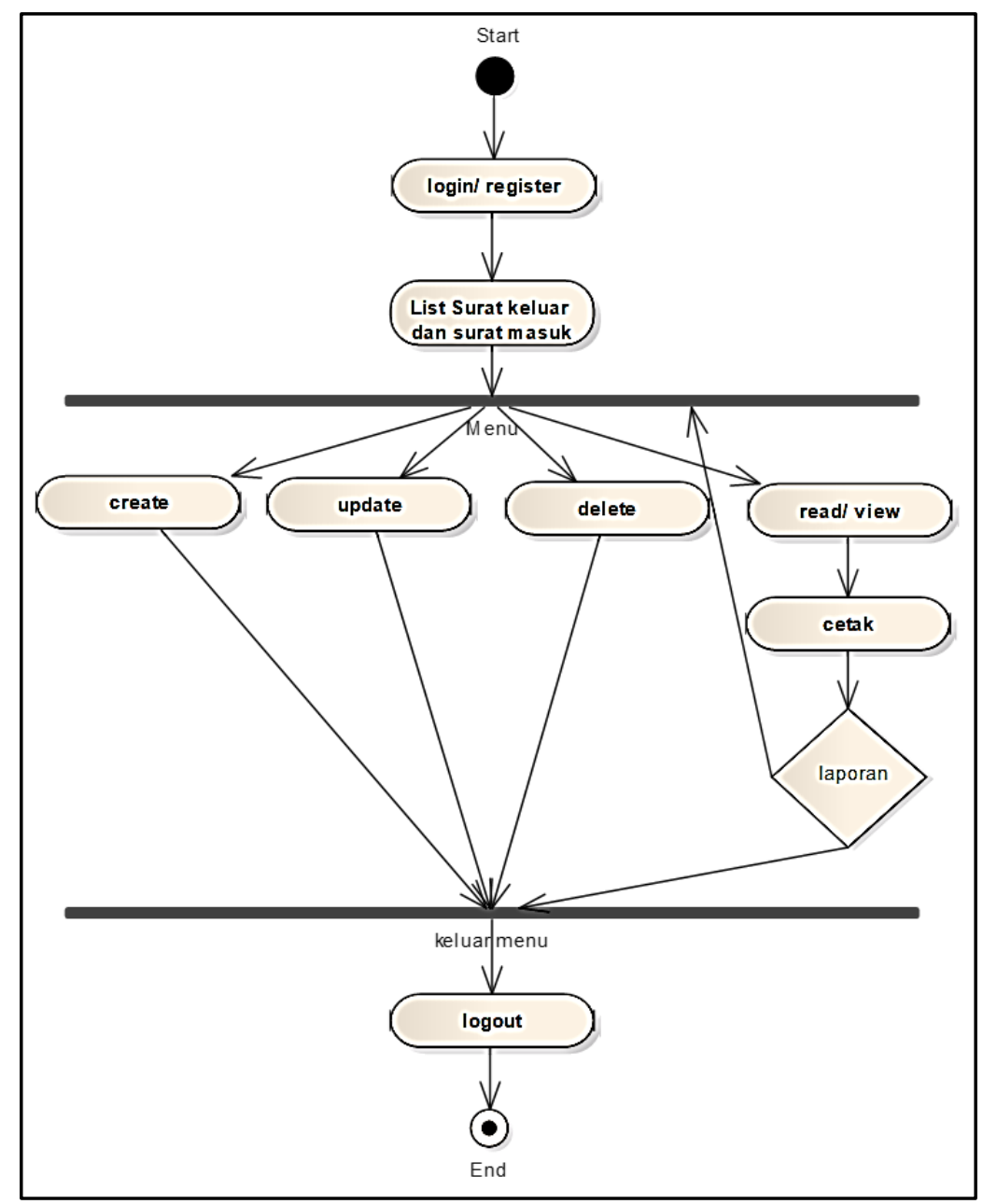

Gambar 3. Activity Diagram Agenda Surat Berbasis Filing System

\section{B. Design Interface Sistem}

Login menu yang paling umum yang ada di aplikasi apapun untuk mengendalikan isi dari aplikasi tersebut tetap terjaga. Gambar 4 merupakan form login untuk admin, dan staf atau agendaris. Pada form ini, staf harus login dengan akun yang sudah didaftarkan sebelumnya lalu kelik masuk. Menu ini adalah menu utama ketika agendaris ingin melakukan kegiatan penagendaan harus masuk kemenu login dulu agar dapat masuk ke menu beranda. Menu ini juga akan tampil ketika kita pertama kali daftar akun ketika sudah ada akun kita tidak perlu login lagi karna sudah otomatis.

Pada halaman ini Gambar 5 menampilkan list masuk untuk melihat semua data surat yang masuk pada hari itu juga. List surat masuk adalah menu daftar dimana surat yang sudah diinputkan akan tampil dimenu ini. Menu ini adalah list surat masuk dimana menampilkan beberapa surat masuk yang sudah agendaris inputkan dimenu ini juga kita dapat melakukan pencarian fiter searching, dengan metode Filing System. Fungsi dari Filing System adalah untuk sebuah instansi maupun organisasi jadi lebih mempermudah dalam pencarian arsip serta menghemat tempat penyimpanan arsip.
Gambar 6 merupakan form input data surat masuk. Menu ini adalah menu penginputan surat keluar ketika instansi meminta surat balasan kepada instansi tersebut. Menu ini adalah menu yang menampilkan beberapa surrat keluar, dimenu ini juga agendaris dapat mencari surat keluar yang diperlukan dengan mudah karna sudah dilengkapi fitur search. Menu ini adalah menu penginputan surat masuk ketika perusahaan atau instansi mendapatkan surat masuk dari instansi lain. Input surat masuk fitur utama pengagendaan surat masuk biasanya surat undangan, edaran, lamaran, dan lain lain.

List surat keluar (Gambar 7) adalah menu daftar dimana surat yang sudah diinputkan akan tampil dimenu ini. Pada halaman ini, me nampilka $\mathrm{n}$ form list surat keluar pada priode tertentu yang sudah diinputkan. Menu ini adalah menu yang menampilkan beberapa surrat keluar, dimenu ini juga agendaris dapat mencari surat kelaur yang diperlukan dengan mudah karna sudah dilengkapi fitur search. adapun surat keluar mencakup pencatatan surat, kosep surat kedalam buku agenda khusus surat keluar yang dikirim ke instansi lain. 
Aplikasi Agenda Surat Masuk dan Surat Keluar Dispora Kota Bandar Lampung

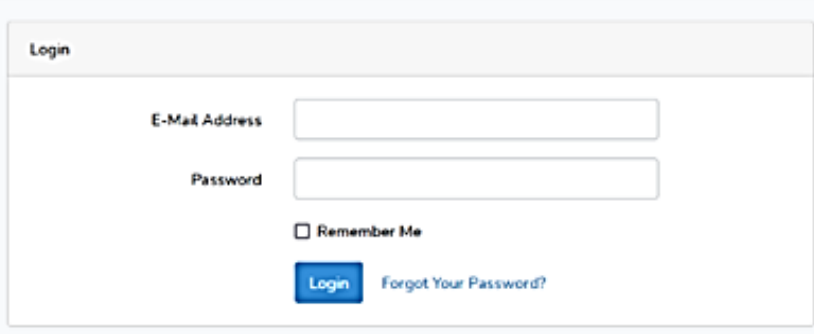

Gambar 4. Tampilan Login Aplikasi Agenda Surat Keluar dan Surat Masuk Berbasis Filing System
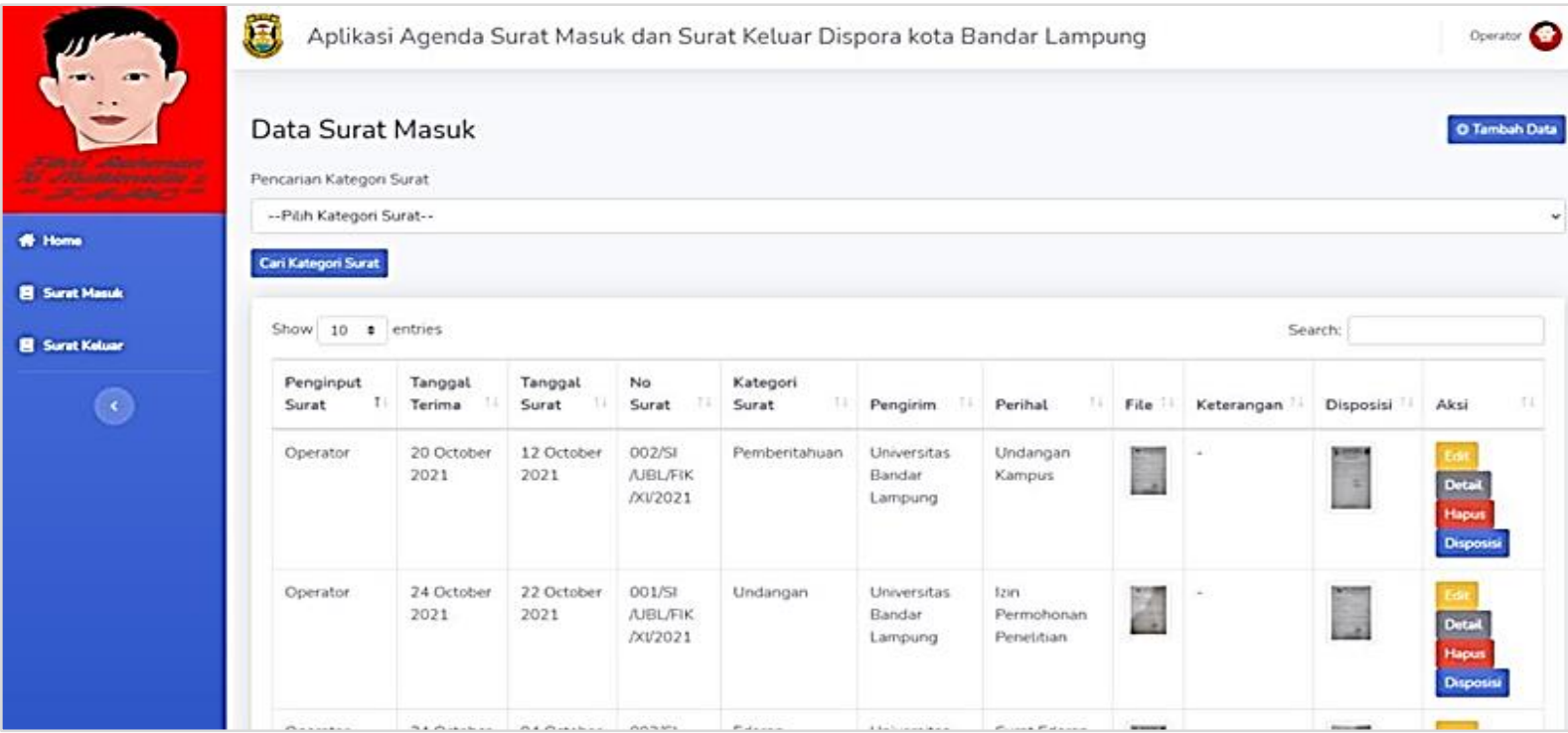

Gambar 5. Tampilan Data Surat Masuk Aplikasi Agenda Surat Keluar dan Surat Masuk Berbasis Filing System
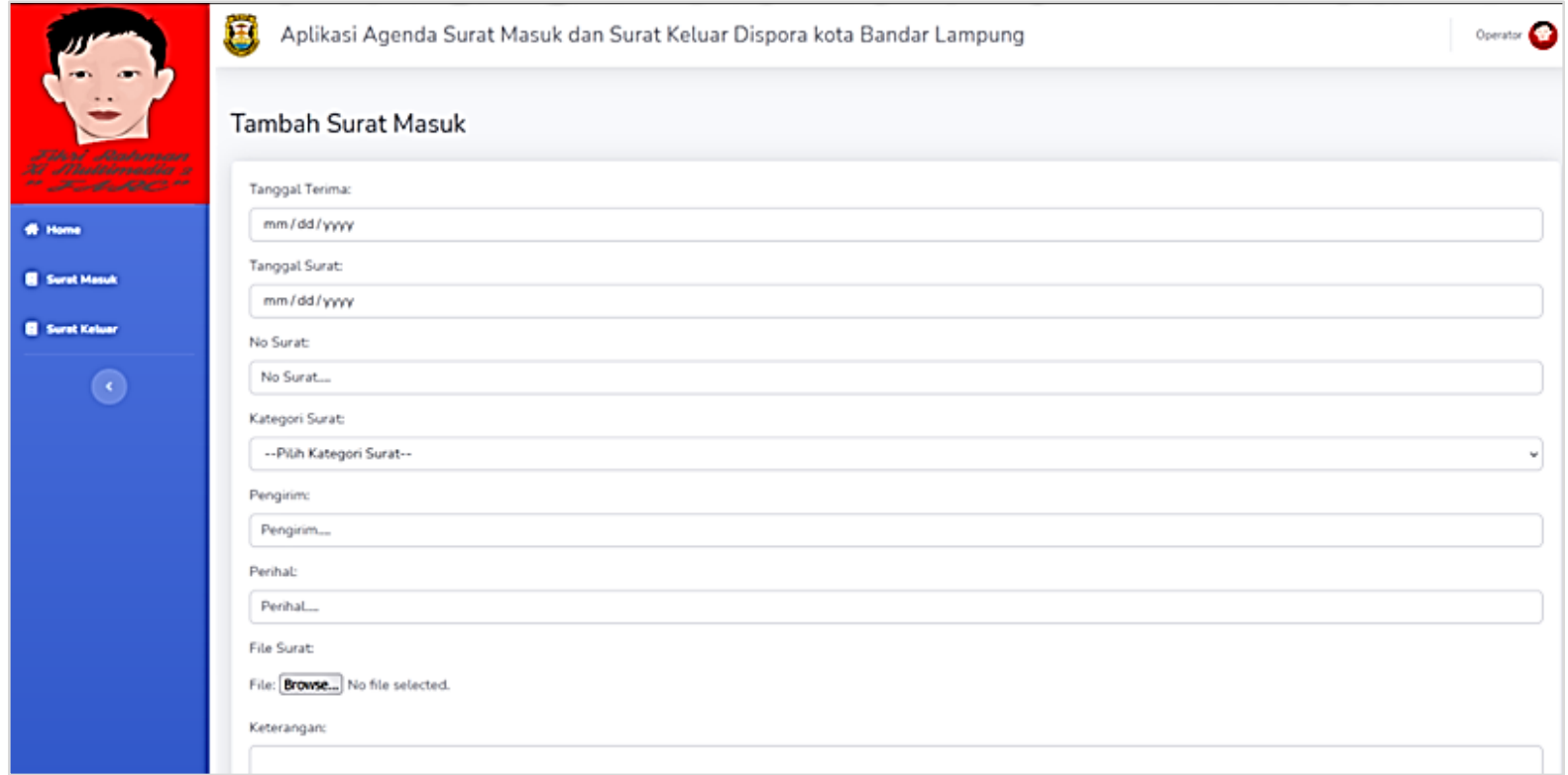

Gambar 6. Tampilan Input Surat Masuk Aplikasi Agenda Surat Keluar dan Surat Masuk Berbasis Filing System 


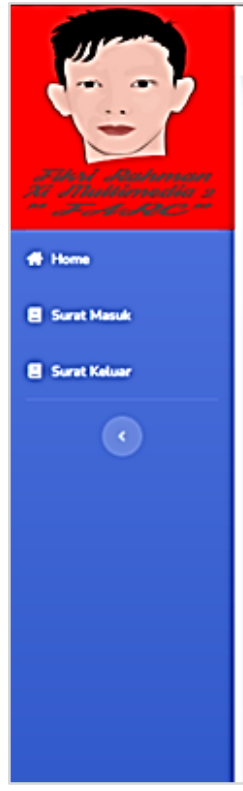

Aplikasi Agenda Surat Masuk dan Surat Keluar Dispora kota Bandar Lampung
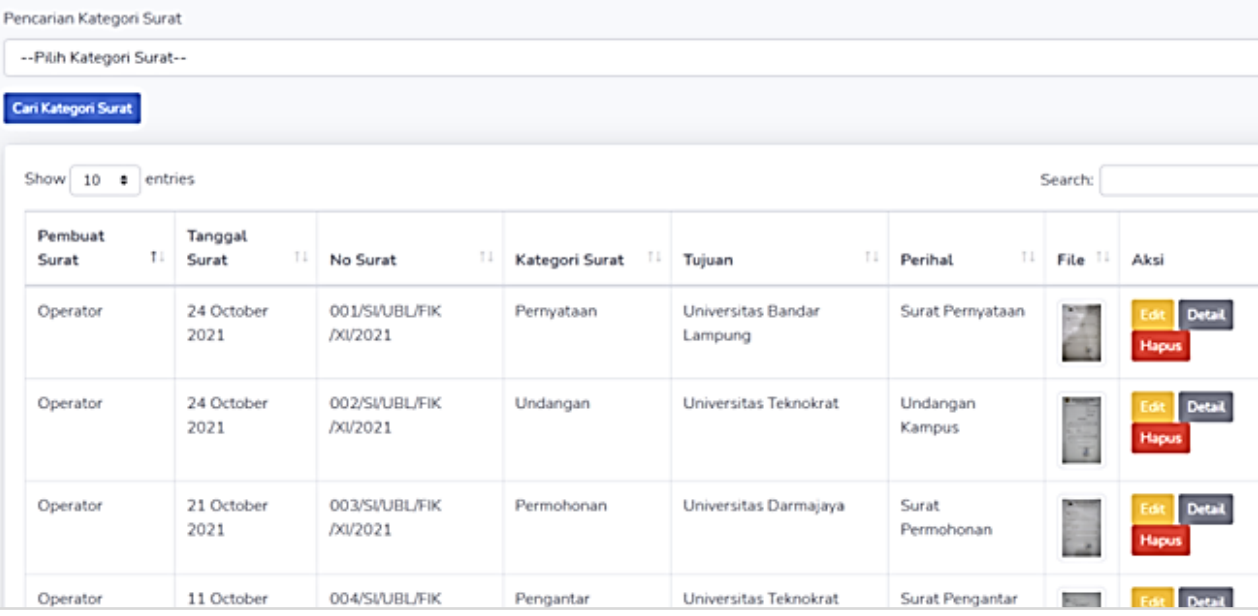

Gambar 7. Tampilan Data Surat Keluar Aplikasi Agenda Surat Keluar dan Surat Masuk Berbasis Filing System
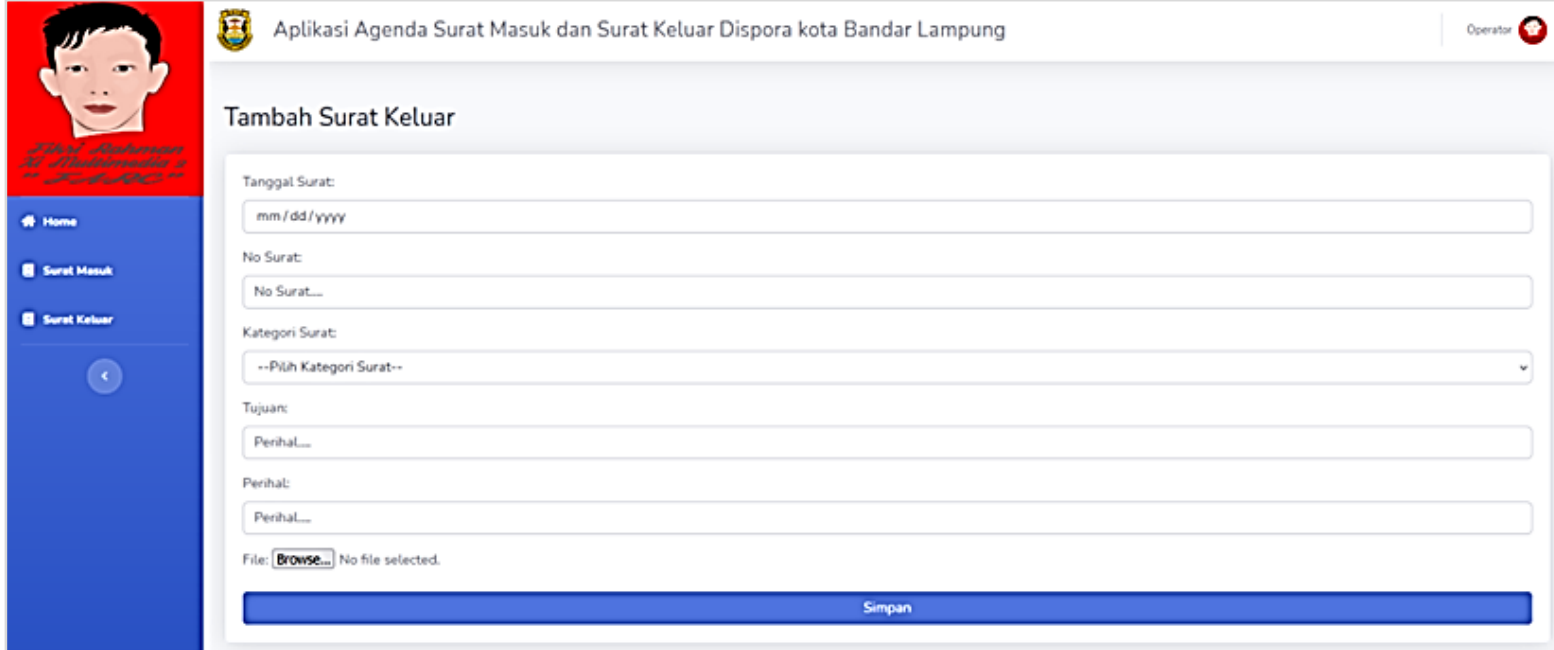

Gambar 7. Tampilan Input Surat Keluar Aplikasi Agenda Surat Keluar dan Surat Masuk Berbasis Filing System

List Surat Keluar (Gambar 7) adalah menu daftar dimana surat yang sudah diinputkan akan tampil dimenu ini. Pada halaman ini, menampilkan form list surat keluar pada priode tertentu yang sudah diinputkan. Menu ini adalah menu yang menampilkan beberapa surrat keluar, dimenu ini juga agendaris dapat mencari surat kelaur yang diperlukan dengan mudah karna sudah dilengkapi fitur search. adapun surat keluar mencakup pencatatan surat, kosep surat kedalam buku agenda khusus surat keluar yang dikirim ke instansi lain.

Input Surat Keluar (Gambar 8) sama seperti fitur input surat masuk, hanya saja surat keluar biasanya surat balasan atau surat yang ditujukan untuk instansi lain. Pada halaman ini, menampilkan penginputan surat keluar bisa dalam bentuk edaran, undangan, atau surat balasan dll. Menu ini adalah menu penginputan surat keluar ketika instansi meminta surat balasan kepada instansi tersebut.

\section{Kesimpulan}

Dari penelitian ini disimpulkan bahwa aplikasi surat keluar dan surat masuk berbasis Filing System ini dapat mempermudah proses kegiatan pengagendaan dalam instansi. Dengan aplikasi ini juga dapat menghemat media penyimpanan, waktu, dan tenaga tanpa repot mencari berkas di lemari dan dibongkar kaerna aplikasi ini dapat menyimpan hardcopy dengan cara di scan lalu di upload, penyimpanan big space database sehingga tanpa harus bertumpuk di lemari penyimpanan.

\section{Daftar Pustaka}

[1] Charis, M. (2009). Sistem Informasi Pengelolaan Surat Masuk Dan Keluar Dengan Visual Foxpro 8.0. Sistem Informasi Pengelolaan Surat Masuk Dan Keluar Dengan Visual Foxpro 8.0, 22 - 30.

DOI http://dx.doi.org/10.36448/expert.v11i2.2254 e-ISSN 2745-7265 p-ISSN 2088-5555 EXPERT Vol. 11 No. 2 December 27, 2021 - Hal. 172 
[2] Susanty, W., Thamrin, T., Erlangga, E., \& Cucus, A. (2012, June). Document management system based on paperless. In International Conference on Engineering and Technology Development (ICETD).

[3] Firman, A., Wowo, H. F., \& Najoan, X. (2016). Sistem Informasi Perpustakaan Online B Berbasis Web. Sistem Informasi Perpustakaan Online Berbasis Web, 29-36.

[4] Ishak, R., Setiaji, Akbar, F., \& Safudin, M. (2020). Rancang Bangun Sistem Informasi Surat Masuk Dan Surat Keluar Berbasis Web Menggunakan Metode Waterfall. 198-209.

[5] mbizmarket, p. (2020, juni 10). ini perbendaan Filing System dan filing cabinet. Retrieved from mbizmarket: https://www.mbizmarket.co.id/news/fillingcabinet/
[6] Nur'aini. (2019). Pengelolaan Surat Masuk Dan Surat Keluar Di Perpustakaan Stipap Medan. 2234.

[7] Priyadi. (2014). Basis Data., 10_BAB-II,

[8] Priyadi. (2014). Structure Query Language (SQL). 10_BAB-II, 82 .

[9] Septiani, N. A., \& Haitami, D. (2020). Perancangan Sistem Pengarsipan Surat Masuk dan Surat Keluar pada Desa Kampung Besar Menggunakan Metode Alphabetical Filing dan Chronology System. 514518.

[10] Sibero. (2013). MySQL. 10_BAB-II, 97. 